\title{
Memoria e intertextualidad en la forma límite de la bio-no-vela circular
}

David Hernández

No resulta difícil darle un orden y una cronología a los 111 fragmentos de la novela más reciente de Argueta. Por una sencilla razón: su orden es cronológico, con excepción de dos fragmentos. Ópticamente hay una separación tipográfica visible entre fragmento y fragmento. Además, cada uno de ellos va numerado de manera consecutiva. El que lleva el número "1" aparece con doble función. Primero, asume el papel de prólogo y por eso valoriza indirectamente el texto que sigue, a la vez que da indicaciones de cómo leerlo y legitimar la búsqueda (¿para qué?) emprendida por el autor, que tiende a confundirse con el yo narrativo. Segundo, ese fragmento uno es ya el comienzo del relato, que tiene una curiosa especificación de género en el subtítulo: Bio-no-vela circular. En esta segunda calidad, el fragmento uno dice: "Hay dos imágenes fundamentales en mis primeros recuerdos de niño". (Pág. 9). El prólogo juega una función específica entre la autobiografía del narrador y el poeta, entre la prosa y la construcción poética. Recuerdos vivenciales e historia:

la fuerza de rememoración hace que las confesiones tengan más del poeta que del narrador

en todo caso es momento de no delimitar lo ilimitable. Poesía-prosa, poema-novela, confesión-ficción, memoria-ensayo, navegan en las mismas aguas. Inocencia y maldad igual niñez y poesía, por eso podemos afirmar que no hay poetas enteramente bondadosos ni realistas sino poetas de la verdad, aunque ésta sea inventada; y por ello el poema es considerado como reducto maligno o expresión radical que se revierte en una especie de delito contra la sociedad

el escritor-poeta dice cosas a sabiendas que perjudica el ritmo cotidiano de la vida o no es poeta; te cagás en la tuya y en la del vecino, pero

1 Siglo de O(g)ro, Págs. 9-10. 
no por puro gusto sino para beneficio de los que ignorás ya sea porque no han nacido o porque viven en mundos desconocidos

el poeta es historia, el narrador la escribe ${ }^{1}$

Estos enunciados, que en su disposición tipográfica evocan el poema en prosa, permiten situar desde el fragmento 1 el alcance del propósito literario que se plantea el texto de Siglo de O(g)ro. Los clásicos modernos, lo mismo Marcel Proust que James Joyce, Robert Musil e Ítalo Svevo en la novela, que Rainer Maria Rilke como poeta y Walter Benjamin en los fragmentos de su experimento autobiográfico Berliner Kindheit um Neunzehnhundert, exploraron los dilemas de la identidad individual en un medio privilegiado: la memoria.

Desde A la recherche du temps perdu, la reconstrucción del sujeto apareció como una desesperada y esperanzada apuesta realizable en el proceso de rememorar. La unidad del sujeto, siempre amenazada por la pluralización de la individualidad, apareció como el efecto ejercido por la memoria sobre la identidad. Como lo argumenta Samuel Beckett en su estudio sobre Proust, la memoria forma algo así como un código, preprogramado para la maquinaria de la percepción. La memoria es parte de la especie de equipo que hace de los modos de percibir un hábito: el hábito resulta así, en la interpretación de Beckett, la forma práctica en que la memoria funciona. El gran logro de Sigmund Freud fue, ciertamente, demostrar la separación entre sistema de percepción y memoria. Pero lo que estaba en juego para Proust, en su Recherche, lo supo precisar así Beckett: "En el tiempo creativo y destructivo Proust se descubrió como artista: 'Entendí la significación de la muerte, del amor, de la vocación, de las alegrías de la inteligencia y de la utilidad del dolor". ${ }^{2}$

Tan características como la autorreflexividad, la exploración del rendimiento de la escritura novelistica, la dislocación de las estructuras narrativas y la problemática del sujeto individual integrado, visible en el trabajo sobre la memoria de los clásicos modernos, fueron los trabajos en el terreno de los marcos sociales de la memoria de Maurice Halbwachs. En su teoría de la memoria Halbwachs le dió a la categoría espacio una beligerancia que había perdido: la capacidad (individual) de recordar la hizo depender del transfondo (social) sobre el que se dibuja, y la extendió a los participantes de la memoria colec-

2 Becket, Samuel, Proust (1931). Zürich, Arche 1960, Pág. 65. 
tiva. Después de la Segunda Guerra Mundial, las terribles experiencias unidas a ella (Holocausto, masacres, exterminio) condujeron a replanteamientos acerca de recuerdo y memoria. Los fenómenos de la represión de la historia de la memoria, para no estar expuestos al recuerdo y para que no haya así realmente responsabilidad, se hicieron notar muy pronto.

En el reciente debate de los historiadores alemanes se ha llegado a plantear, por eso, el poder analítico de una forma de recuerdo capaz de mirar "científicamente" lo pasado como historia, sin ser de ninguna manera moralmente neutral. En materia artística, contra las viejas polaridades modernas (formas de elite/cultura de masas, sujeto/objeto), ha sido precisamente un medio como el cine el que consiguió enfrentar con éxito la reconstrucción de la memoria (identidad) individual e investigar los enigmas de la "vocación" artística. El film Otto e mezo, de Federico Fellini, es prueba de ello. Al mismo tiempo, dentro de los procesos literario y cultural latinoamericanos, los monumentos del nuevo arte de la memoria - el episodio de la peste del olvido en Cien años de soledad de Gabriel García Márquez, y el teatro de la memoria en Terra nostra de Carlos Fuentes - han marcado con claridad la distancia en varios sentidos - artística, epistemológica y en relación con la articulación de intereses sociales - que impide asimilarlos a los productos del proyecto clásico del modernismo. ${ }^{3}$

Es depués de estos desarrollos y resultados y después de la más dura crisis social y política, de la guerra más cruenta que haya enfrentado en su historia la población de El Salvador, que el narrador de Siglo de $O(g)$ ro emprende su experimento que reconstruye su memoria como memoria del país, a través del hallazgo de una respuesta a una preguntas indirectamente tematizadas: ¿Por qué puedo contar? ¿De dónde tengo ese permiso y el poder para hacerlo? Ya en el título mismo de la novela hay un obvio juego intertextual. Siglo de $O(g)$ ro no es solo el utópico Siglo de oro que podía evocar don Quijote en su discurso a los pastores de cabras (La Edad de Oro) o el supuesto momento culminante de las letras españolas (Siglo de oro). Es también réplica a la revista de José Martí, pensada y escrita para niños: La edad de oro. Y el ogro es no solo el de los cuentos de hadas, ni es el leviatán abstracto de La cuisinière et le mangeur d'hommes (1975) de André Glucksmann, de donde salió el ogro benefactor de Octavio Paz. El ogro, en la bio-no-vela circular de Ar-

3 Bradbury, Malcom/MacFarlane, James (Editores), Modernism. Hardmondsworth, Pinguin Books, 1976. 
gueta, como alegorización personificadora, encarna la violencia destructora organizada desde el Estado. A quien vivió la "infancia salvadoreña en 1940", le tocará vivir más tarde los tiempos de la violencia destructora estatal. Es depués de la guerra que el narrador puede contar su infancia para saber por qué tiene el poder maravilloso de contar. De escribir las historias que ha narrado (o habrá contado como novelista adulto).

Como parte de las innovaciones metodológicas de los años 60, la teoría de la intertextualidad, y la transformación de ese concepto en una categoría analítica, ha venido sirviendo desde los años 70 para estudiar la calidad de los textos literarios. Sobre los desarrollos más recientes de las investigaciones intertextuales, Carlos Rincón señala el vínculo entre intertextualidad y memoria, con incursiones hacia la tipología de la cultura y la teoría cultural:

De más interés todavía (...) es la consideración de las referencias intertextuales de un texto como su propia memoria. Constituye un camino productivo e innovador, al hacer así de la literatura, desde el punto de la memoria, el arte mnemotécnico por excelencia. Los textos literarios resultan en esa perspectiva productos de un arte de memoria y, al mismo tiempo, una nueva lectura signica de la cultura del libro disponible. El texto concreto actúa como boceto de un microespacio de la memoria, capaz de connotar simultáneamente el macroespacio de la memoria de una cultura. ${ }^{4}$

Esta nueva interpretación del concepto de intertextualidad permite situar, respecto a la novela de Argueta, tanto la cuestión de la forma fragmentaria del texto, la cuestión del género, las exigencias al lector, como el funcionamiento del texto en calidad de "boceto de un microespacio de la memoria" que restituye al mismo tiempo el "macroespacio de la memoria" de la cultura de El Salvador.

¿Por qué, a pesar de ejemplos como ese, el recurso al fragmento narrativo en la bio-no-vela? Se trata de una representación concientemente interrumpida a cada paso de una infancia, pero no porque Argueta renuncia sencillamente a una elaboración amplia y sistemática de lo narrado. El carácter fragmentario conlleva una especificación crítico-experimental en dos sentidos. Busca ser, en primer lugar, la forma de dar cuenta del caracter fragmentario y discontinuo de los recuerdos: "El momento se quedó grabado en la memoria" (261),

4 Rincón, Carlos, La no simultaneidad de lo simultáneo. Pág. 183 
como lo dice la primera frase del fragmento 83; "Desde entonces he fijado en mi memoria mi tendencia a volver por mis amigos aunque me arriesgue a todo", comienzo del fragmento 79. Y segundo, pide del lector la realización de una doble tarea. No sólo debe descifrar durante la lectura línea por línea cada uno de los fragmentos del texto. La política de la representación puesta en práctica en la bio-no-vela supone que el lector, al mismo tiempo, llene intermitentemente vacíos de el salto de fragmento a fragmento; es decir, en última instancia, que yuxtaponga, monte (en el sentido de "montaje"), arme o situe en serie los fragmentos vitales en el desarrollo de una infancia (y una vida). La corriente narrativa se interrumpe con cada nuevo fragmento; el lector dota de ritmo y acentos a la estructura que él crea en la lectura. En cada fragmento está situado un "presente". Con la lectura del siguiente fragmento ese presente se hace pasado del niño cuya vida se evoca.

Las obras del arte narrativo en América Latina y en El Salvador constituyen entre sí un sistema de relaciones, con límites fluidos, en donde la regla son las formas limítrofes o mezcladas, mixtas. En Siglo de $O(g)$ ro las matrices de la biografía, de la autobiografía, de la novela y los límites entre ellas, se desdibujan de manera creciente. Esa es la función del no, de la negación, entre los guiones que hacen de él el lazo de unión entre lo (auto)biográfico y lo (no)velado; no graphein = escribir, sino hechos novela, en el sentido, a la vez, de novelar, y de desvelar = eletheia, quitar el velo, en lugar de velar. De manera que la matriz moderna de pensamiento (las fronteras entre de género) es rebasada en busca de otra forma de communicación social y de transmisión estéticamente más adecuada. Las relaciones de tensión entre la meta (auto)biográfica y la forma novelada que se ha hecho explotar (no-vela) se convierten en fuerzas impulsoras del escrutinio de la memoria, de sus poderes de olvidar y preservar.

La cuestión de la intertextualidad, como compenetración difusa del texto por memorias, transformaciones, ecos de otros textos, se plantea en la lectura de dos maneras distintas. La primera está directamente vinculada con el problema de la "cita" y "el citar". Pues dentro del texto de diversos fragmentos algunos "agregados" estan impresos con otra tipografía, en un tipo de letra más pequeña, encabezados con un título propio. Se trata de nueve textos incluidos en los fragmentos 14, 32, 36, 44, 46, 68, 73, 91 y 106. Los dos primeros, "La gota de coral" y "El basilisco"; y el sexto, "La carreta bruja" (fragmento 91), tratan de creencias populares que forman parte de la socialización familiar de “Alfonso Trece Duque", el nombre propio paródico del narrador. En todos los 
demás casos (fragmentos 44 y 46: "La Siguanaba” I y II; fragmentos 68: "El Cadejo", etc.), la cita de la forma mítica emerje de la literatura (post)moderna de la memoria practicada por Argueta: lo mítico no es interpretado psicoanalítica, etnográfica, mágico-realísticamente, sino que, al marcar con ayuda del relato, en donde se le incluye, el puesto que tiene en la vida se constituye estéticamente y a la vez como realidad vivida. Se produce así, con la reconstrucción de figuras o relatos mitológicos un excedente, dotador de identidad, en materia de potencial estético: "yo soy" aquel que sabe desde niño quiénes son la Siguanaba, el Cadejo; yo soy el que sé sus historias y quien las puede contar a quienes (de alguna manera) ya saben quiénes son... Por eso, como los relatos mitológicos, transmitidos dentro de la tradición oral, la bio-no-vela es circular. Es también por eso que la última narración mítica citada es la de El Cipitillo: "Hijo de la Siguanaba y protegido del dios Tlaloc, el Cipitillo es un niño-duende destinado a vivir para siempre." (338-340) Inventio significa aquí versión de una materia conocida, la performance narrativa va unida a una estética de la contingencia.

La segunda forma de presencia de esa concepción de intertextualidad da una respuesta directa a la pregunta que orienta la bio-no-vela: ¿por qué puedo contar? El mundo del niño Alfonso Trece se semeja en un punto al del director de cine Guido Anselmi en Otto e mezo de Fellini. Guido es asaltado en el curso de la película por recuerdos de su infancia, una infancia en que estuvo rodeado de mujeres. El mundo del yo narrativo en el Siglo de $O(g) r o$ es un mundo poblado y regido por mujeres: no hay casa "paterna" sino casa-de-laabuela-de-la-madre-con-las-otras-muchas-mujeres. De esa manera, la constelación narrativa construida con la abuela, con la madre (Crista) y con la mujer que trabajaba para la madre (Chela), se constituye y despliega como fuente y transmisora de relatos (de textos). El fragmento 67 dice:

CHELA fue otra mujer importante en mi vida, Graciela Zelaya, trabajadora al servicio de la madre, con quien tuve acceso a las canciones, principalmente el tango, cuyas letras melodramáticas y sus historias de muerte las relaciono con las noticias rojas de los periódicos. La forma de cantar o narrar impacta mi corazón de niño. ${ }^{5}$

El retrato que ofrece de Chela la muestra tanto con funciones de reproducción doméstica dentro de la casa, como en calidadad de transmisora de poesía: 
Las otras narraciones eran "Las mil y una noches". Le pedía que me explicara por qué el artículo indeterminado "un" no coincidía con el plural "noches", pero Chela no lo podía aclarar: "Así se llama y punto".

Esta preocupación semántica quedaba opacada ante la esencialidad de Chela: A lo mejor cuando estés grande, que avancés en tus estudios, vos me lo vas a explicar, dice. Era una trabajadora de la costura que también se ganaba la tortilla vendiendo en el volcán, cada fin de semana, la ropa que hacía la madre; en todo caso, fue uno de mis fantasmas benefactores, nunca supé cómo en su humildad llegó a conocer tantas canciones y cuentos que impactaron mi infancia; pero la narración oral me estimuló para descubruirlos después en libros y cancioneros populares. Ediciones precarias, muchas veces, que adquiría de vez en cuando en las ferias de San Miguel. ${ }^{6}$

En la performance de contar un cuento, la densidad de los fenómenos de interacción entre narrar y escuchar, hace que sea la audiencia la que reconozca si una historia está o no bien contada, y experimente como placer estético el encantamiento del relato como relato. La audiencia es participante en el relato, de manera activa con la imaginación, dándole una realidad imaginaria muy real a lo relatado. El placer del relato es inseparable de la entrega a ese tipo de actividad:

No cabe duda que Chela tenía condiciones para contar. Y me fue tan familiar el nombre de Scherezada, dejando en suspenso cada noche un cuento para contener su muerte. Inclusive quizás de ahí vino la influencia de dejar cortadas las narraciones de películas que le hacía a mis hermanas, películas que tenía oportunidad de ver en el Teatro Nacional y Principal. Tuve una gran fuente de conocimiento en el cine pero quizás fue mayor el aporte de la costurera Chela, ayudante de la madre que salía bajo las lluvias y las tormentas a vender al volcán Chaparrastique la ropa que fabricaba Crista. Chela me hizo advertir otro mundo en aquellas condiciones de vida sencilla, de temores, soledad y aislamiento, y coincidió con la madre en revelarme otras dimensiones de la vida en una literatura fantástica pero que me parecía $\tan$ real. $^{7}$

¿Por qué puedo contar? La razón de ello me la proporciona lo escrito en esta

6 Ibid., Págs. 207-208

7 Ibid., Pág. 208 
bio-no-vela: porque soy el descendiente de esta estirpe de narradoras maravillosas y me alimento de la interminable reserva de la tradición oral:

Mientras Crista insistía con los poemas y prosas morales, Chela se inclinaba por la narrativa de ficción, describía a "Scherezada", a Simbad, a Ali Baba, a Aladino, los ogros de un solo ojo, las botas de siete leguas, las brujas comedoras de niños y los gatos con botas. La magia de los cuentos los contrastaba con los cuentos de la abuela: el Cipitillo, la Siguanaba, el Justo Juez de la Noche, el Cadejo, la Carreta Bruja, la Coyota Teodora. Estos me revelaban la irrealidad palpable y amenazante, los de Chela me impulsaban a descubrir el mundo. Crista ofrecía la emoción íntima.

No sé cómo había hecho Chela para tener acceso a canciones y cuentos, pero ello, junto con los poemas de la madre, permitieron conocer la dimensión del universo, que años más tarde debía recorrer en la realidad y con la imaginación. Esos mundos reveladores de tesoros escondidos y que descubrirlos significan grandes aventuras. Así se formó mi vocación por la literatura y los libros. ${ }^{8}$

Memoria colectiva, hecho narrativo, hecho ficcional: las "palabras de la tribu" en el mundo del narrador son las de El Salvador, mirándose en las páginas del libro. La memoria del niño es el espacio en que resuenan, se entrelazan, se hacen eco las potencialidades de esas "fuentes" narrativas. El lugar de la narración no se puede desvincular de la vida del narrador:

Recuerdo a Chela y a la madre en las horas nocturnas; Chela rinde cuenta sobre las ventas y la madre prepara un café para evitar que se resfríe, empapada por el agua lluvia, mientras yo jugaba con su hijo Tito y con Erlinda, hija menor de Chela. Esta me describió por primera vez el Cadejo, así como ella lo vió lo describo en uno de mis cuentos dirigido a niños salvadoreños que viven en Estados Unidos.

El Cadejo acompañaba a Chela en sus viajes por la oscuridad de los montes. "El Cadejo me cuida que nadie vaya a hacerme un mal por esos caminos de Dios". Y de alguna manera yo también quería al Cadejo, por ser bueno con Chela, aunque nunca pude verlo.

8 Ibid., Págs. 208-209.

9 Ibid., Págs. 211-212. 
“Cómo se sabe que el Cadejo no es un perro?”, le pregunto. “Por el sonido de sus pasos, pues tiene pezuñas, como un caballito y los ojos colorados." En todo lo demás parece un perro. Y que hay un Cadejo Negro y un Cadejo Blanco pero que a ella sólo le sale el Negro y no sabe por qué nunca se le presenta el Blanco: "Todo Cadejo, cualquiera que sea el color es bueno", responde. ${ }^{9}$

De esta forma la novela de Argueta tematiza la presencia abiertamente reivindicada e incorporada de la cultura indígena en su diferenciación, con sus conocimientos y sabidurías propios, y con su propio arte de contar, en un mundo turbado de la postguerra, actual, recién salido de la guerra civil que azotó al país por doce años:

Es un nahual, o lo que queda de los nahuales, el animal mito que cuida a las personas. En otr as culturas se les llama "ángel de la guarda"; la gente de nuestro pueblo tiene sus propios protectores espirituales. "Lo he visto varias veces cuando me sigue, aunque no le gusta que uno vea para atrás". Habla con naturalidad mientras nosotros nos morimos de miedo. "Claro no se ve bien por la oscuridad pero a veces la luz de las estrellas alumbra fuerte o puede ser en una noche de luna". Nos lo describe: Se trata de una especie de perrito, pero que en lugar de pezuñas tiene casquitos como los venados, se siente en el taconeo, eso es lo que permite identificarlo y no confundirlo con un perro. Sus ojos brillan como si fueran carbones encendidos, si una se detiene cuando viene detrás, él también se detiene. Si una corre él también corre. ${ }^{10}$

La búsqueda literaria personal de Manlio Argueta alcanza así una dimensión restablecedora de memoria nacional reprimida, y se dota de una nueva función terapéutica. Dentro de la teorización de Freud en sus Vorlesungen zur Einführung in die Psychoanalyse (1915-1917), el trauma es un fenómeno con características específicas:

Wir nennen so ein Erlebnis, welches dem Seelenleben innerhalb kurzer Zeit einen so starken Reizzuwachs bringt, daß die Erledigung oder Ausarbeitung desselben in normal-gewohnter Weise mißglückt, woarus dauernde Störungen im Energiebetrieb resultieren müssen. (Llamamos trauma a una vivencia que somete en un espacio de tiempo la vida anímica a un crecimiento tan fuerte de estímulos que el

10 Ibid., Pág. 212.

11 Freud, Sigmund, Gesammelte Werke. Tomo XI., Pág. 284 
control o la elaboración de aquél en la acostumbrada forma normal fracasa, de donde resultan interrupciones permanentes en el aparato energético. $)^{11}$

La intensidad del trauma, la incapacidad del sujeto para reaccionar ante él mismo y sus consecuencias patógenas de larga duración, se traducen en una oleada de estímulos que, según la fórmula de Jean Laplanche y Jean-Bautista Pontalis, "en comparación con la tolerancia del sujeto y sus capacidades de controlar síquicamente este trauma y de asimilar esos estímulos, son excesivas." ${ }^{2}$. La presencia de la cultura indígena como parte integral de la cultura salvadoreña en Siglo de $O(g) r o$ se inscribe dentro de un proceso de recordar activamente guiado. Ya no es cuestión de lo que se ha olvidado (fases infantiles, inconsciente, la corriente pura del tiempo), sino del uso de la memoria para servir a un futuro mejor y - en el sentido de Benjamin - a la "redención" de lo reprimido.

En el fragmento 106 de la bio-no-vela circular, se relata el traslado de la familia a una casa, por fin propia, que la abuela ha comprado ("A la calle Colón se mudaron todas las mujeres y el poeta, cuyo traslado se registra a mediados de 1939, es donde habita en la actualidad la madre a sus noventa años". Pág. 337). Está situada en el espacio urbano de San Miguel, pero es, al mismo tiempo, periferia o frontera entre ciudad y campo, donde existe la posibilidad para el narrador de seguir coexistiendo con las figuras de la mitología indígena como el Cipitillo o el Cadejo. Uno de sus hijos, Tarquino, explica a la abuela de qué clase de casa se trata. El comentario es del narrador:

Es difícil encontrar una casa aceptable, la única que encontré es una de adobes, solitaria, sin agua potable, sin luz eléctrica, no tendríamos vecinos; sólo guineal a un lado, milpas al otro, potrero al lado del volcán y matorrales enfrente - dice Tarquino. Era el lugar preciso para convivir con el Cipitillo, el Cadejo y tantas deidades de la cultura nahuat. ${ }^{13}$

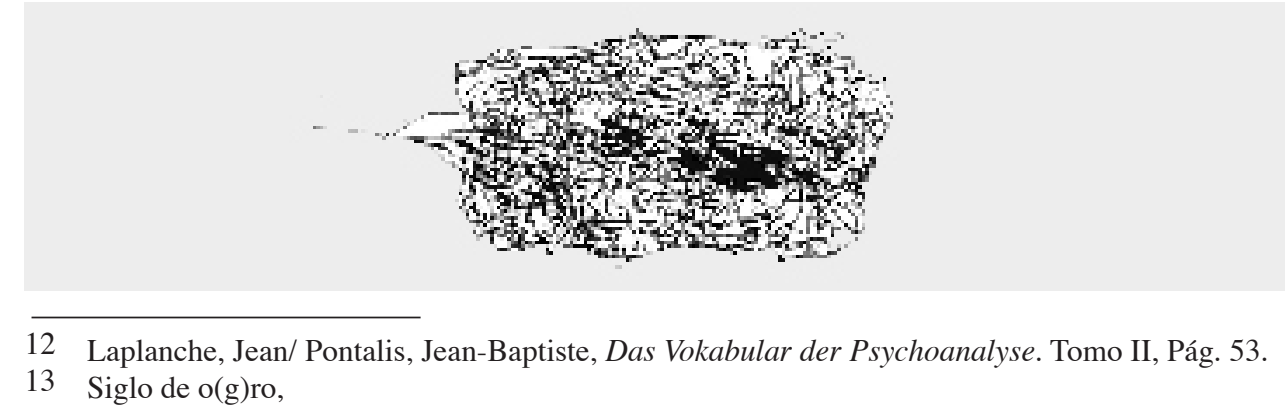

